\title{
Usefulness of white blood cell count to mean platelet volume ratio in the prediction of SYNTAX score in patients with non-ST elevation myocardial infarction
}

\author{
Serkan Sivri ${ }^{1}$, Erdogan Sokmen², Mustafa Celik \\ Sinan Cemgil Ozbek ${ }^{4}$, Alp Yildirim ${ }^{5}$, Yalcin Boduroglu ${ }^{6}$
}

\begin{abstract}
Objective: White blood cell (WBC) count to mean platelet volume (MPV) ratio (WMR) is associated with major adverse cardiovascular events in patients with non-ST elevation myocardial infarction (NSTEMI). We aimed to compare WMR between NSTEMI patients and matched-controls and to evaluate its predictive value on SYNTAX score.

Methods: Total 175 patients with NSTEMI and 160 age and co-morbidity matched subjects were recruited in our study. WMR was compared between the patient and control groups. The patient group was further subdivided into 3 tertiles according to SYNTAX scores as follows: low SYNTAX score tertile (score $\leq 22,141$ patients); intermediate SYNTAX score tertile (score between 23 and 32, 20 patients); and, high SYNTAX score tertile (score $\geq 33,14$ patients). WMR was further assessed among the tertiles.

Results: WMR was significantly greater in the patient group compared to the control group $(p<0,001)$. WMR among low, intermediate and high score tertiles were calculated to be $890 \pm 26,1090 \pm 042$ and $1500 \pm 65$, respectively $(\mathrm{p}<0,001)$. In receiver operating characteristics (ROC) analysis, WMR $>960$ predicted a SYNTAX score $\geq 23$ with $80.6 \%$ sensitivity and $67.6 \%$ specificity (AUC: $0.756 ; 95 \% \mathrm{Cl}: 0.685-0.818 ; \mathrm{p}<0.0001$ ) and a WMR $>1360$ predicted a SYNTAX score $\geq 33$ with $71.4 \%$ sensitivity and $93 \%$ specificity (AUC: $0.840 ; 95 \% \mathrm{Cl}$ : 0.777 - 0.892; $\mathrm{p}<0.0001$ ).

Conclusions: WMR value was significantly elevated in NSTEMI patients, compared to controls. Higher WMR was associated with greater SYNTAX score in patients with NSTEMI. WMR may be used to predict severity of the CAD and to implement risk stratification in patients with NSTEMI.
\end{abstract}

KEYWORDS: Acute coronary syndrome, Coronary atherosclerosis, SYNTAX score, White blood cell count to mean platelet volume ratio.

doi: https://doi.org/10.12669/pjms.35.3.1017

How to cite this:

Sivri S, Sokmen E, Celik M, Ozbek SC, Yildirim A, Boduroglu Y. Usefulness of white blood cell count to mean platelet volume ratio in the prediction of SYNTAX score in patients with non-ST elevation myocardial infarction. Pak J Med Sci. 2019;35(3):824-829. doi: https://doi.org/10.12669/pjms.35.3.1017

This is an Open Access article distributed under the terms of the Creative Commons Attribution License (http://creativecommons.org/licenses/by/3.0), which permits unrestricted use, distribution, and reproduction in any medium, provided the original work is properly cited.

\section{INTRODUCTION}

Correspondence:

Dr. Serkan Sivri,

Department of Cardiology,

Ahi Evran University Training and Research Hospital, Kirsehir, Turkey.

Email: drserkansivri@gmail.com

* Received for Publication:

* $1^{\text {st }}$ Revision Received:

* $2^{\text {nd }}$ Revision Received:

* Accepted for Publication:
May 13, 2018

May 28, 2018

November 2, 2018

March 28, 2019
Acute coronary syndrome (ACS) is a disease characterized in most of the cases by rupture of atherosclerotic plaque and subsequent complete or incomplete thrombosis of the coronary arteries. ${ }^{1}$ It has still persisted to be the most common reason for death worldwide, despite ongoing amelioration in the rate of mortality. ${ }^{2}$

Previous studies have reported increased admission white blood cell (WBC) count to be a robust predictor of morbidity and mortality in 
patients with ACS.,4 Mean platelet volume (MPV) has long been a byword for the marker of platelet activation. Increased MPV readily translates into more active and thrombogenic platelets than smaller ones., ${ }^{5,6}$ Accordingly, both increased MPV and WBC count on admission was documented previously to have a statistical significance in the prediction of impaired reperfusion and mortality in patients with ACS. ${ }^{78}$

In the present study, we intended to assess WMR, has emerged as a novel inflammatory marker, on admission in patients with NSTEMI, and its further association with SYNTAX score.

\section{METHODS}

A total of 175 consecutive patients who were admitted to the emergency department of our hospital between July 2017 - January 2018 and diagnosed with NSTEMI were recruited in our study. The exclusion criteria were set as follows: lack of patient consent, previously known CAD, significant valvular heart disease or valve surgery, chronic renal failure, recent surgery, use of steroid or non-steroid anti-inflammatory treatment. The diagnosis of NSTEMI was confirmed if patients had typical angina pain lasting 30 minutes, elevated cardiac troponin levels and no ST segment elevation detectable in the electrocardiogram (ECG). Moreover, a total of 160 subjects with no previous history of CAD who were matched regarding age and co-morbidities were employed as control group. Blood sample was obtained on admission from each patient for the measurement of complete blood count, troponin levels, liver and kidney function tests and bleeding profile. Twelve hour fasting serum lipid profiles were measured by standard enzymatic methods. The study was approved local ethics committee and informed consents were obtained from all the participants.

Coronary Angiography and Interventions: All patients were treated by complying with the recommendations of NSTEMI guideline. ${ }^{9}$ Coronary angiography was performed in all patients using the standard techniques. Glycoprotein IIb/ IIIa inhibitor (Tirofiban) was administered to the patients in the catheterization laboratory at the operator's discretion. Decision regarding the implementation of percutaneous coronary intervention (PCI), coronary artery bypass grafting (CABG) surgery or medical treatment was given by a heart team comprising two cardiologists and one cardiovascular surgeon. All PCIs performed in eligible patients were performed using the standard clinical practice and choice between the alternatives of drug-eluting stent or bare metal stent was at the operator's discretion. In most of the patients, stenting of infarct-related artery was successfully fulfilled. Medical treatment or CABG surgery was applied to the rest of the patients.

Assessment of cineangiographic view was performed using Axiom (Siemens Medical Solution, Erlangen, Germany) workstation by two experienced cardiologist blinded to the study data. Each lesion with a diameter stenosis $\geq 50 \%$ in coronary vessels $\geq 1.5 \mathrm{~mm}$ in diameter was scored using the online SYNTAX score calculator. ${ }^{10}$ If the cardiologists disagree about the lesions, the ultimate score was decided by averaging the scores calculated by each cardiologist.

Statistical analysis: SPSS v.22.0 software for Windows (SPSS Inc. Chicago, llinois, USA) was used for the statistical analysis. Continuous variables were expressed as mean \pm standard deviation (SD), while categorical variables were expressed in numbers and percentages. The normal distribution of the data was evaluated by Kolmogorov-Smirnov and Shapiro-Wilk test. Nonparametric variables between groups were compared with the MannWhitney U test or Student's test. The patient group population was further divided into tertiles on the basis of SYNTAX scores calculated. Oneway analysis of variance (ANOVA) test was used for continuous variables, whereas categorical variables were compared with the chi-square test among SYNTAX score tertiles. Receiver operating characteristic (ROC) curve analysis was used to detect the sensitivity and specificity of WMR and its cutoff values in the prediction of SYNTAX score. P value $<0.05$ was accepted to be statistically significant.

\section{RESULTS}

The patient group consisted of 175 NSTEMI patients (mean age: $60.1 \pm 12.0$ years). The control group consisted of 160 subjects (mean age: 59.4 49.6 years). Demographic, echocardiographic and biochemical characteristics of all study population was presented in Table-I. There was no statistically significant difference with regard to age $(p=0.571)$ and such other comorbid factors as diabetes mellitus $(p=0.055)$, hypertension $(p=0.140)$, chronic obstructive pulmonary disease $(p=0,186)$ and obesity $(p=0.261)$ between two groups. Total cholesterol and low density lipoprotein levels were similar between the groups $(\mathrm{p}=0.158$ and $\mathrm{p}=0.105$, respectively), in contrast, high density 
WMR in patients with NSTEMI

Table-I: Demographic, biochemical and echocardiographic characteristics of NSTEMI patient and control groups.

\begin{tabular}{|c|c|c|c|}
\hline Variables & Patient Group ( $n=175)$ & Control Group $(n=160)$ & P-value \\
\hline Age, years & $60.1 \pm 12.0$ & $59.4 \pm 9.6$ & 0.571 \\
\hline $\mathrm{DM}, \mathrm{n}(\%)$ & $57(32.6 \%)$ & $37(23.1 \%)$ & 0.055 \\
\hline $\mathrm{HT}, \mathrm{n}(\%)$ & $94(53.7 \%)$ & $73(45.6 \%)$ & 0.140 \\
\hline COPD, n (\%) & $31(17.7 \%)$ & $20(12.5 \%)$ & 0.186 \\
\hline Obesity, n (\%) & $22(12.6 \%)$ & $14(8.7 \%)$ & 0.261 \\
\hline SYNTAX score & $11,79(0-38.5)$ & - & - \\
\hline $\mathrm{WBC}\left(\times 10^{3} / \mathrm{uL}\right)$ & $9.14 \pm 3.54$ & $8.03 \pm 2.14$ & 0.002 \\
\hline MPV (fL) & $9.68 \pm 1.34$ & $10.71 \pm 0.94$ & $<0.001$ \\
\hline WMR & $960 \pm 37$ & $760 \pm 21$ & $<0.001$ \\
\hline Neutrophile $\left(\times 10^{3} / \mathrm{uL}\right)$ & $6.05 \pm 2.86$ & $4.74 \pm 1.69$ & $<0.001$ \\
\hline Lymphocyte(x103/uL) & $2.23 \pm 1.24$ & $2.50 \pm 0.69$ & $<0.001$ \\
\hline Platelet $\left(x 10^{3} / \mathrm{uL}\right)$ & $220.22 \pm 63.35$ & $266.87 \pm 62.72$ & $<0.001$ \\
\hline Glucose (mg/dL) & $155.28 \pm 78.26$ & $104.37 \pm 56.51$ & $<0.001$ \\
\hline Creatinine (mg/dL) & $1.07 \pm 0.77$ & $0.81 \pm 0.83$ & $<0.001$ \\
\hline Total cholesterol (mg/dL) & $187.57 \pm 42.86$ & $193.79 \pm 40.00$ & 0.158 \\
\hline $\mathrm{LDL}(\mathrm{mg} / \mathrm{dL})$ & $110.20 \pm 36.44$ & $116.61 \pm 34.69$ & 0.105 \\
\hline $\operatorname{HDL}(\mathrm{mg} / \mathrm{dL})$ & $41.10 \pm 14.67$ & $45.53 \pm 13.09$ & 0.001 \\
\hline Troponin (pg/mL) & $441.11(3-10950)$ & - & - \\
\hline CK-MB (ng/mL) & $15.82(0.40-300)$ & - & - \\
\hline $\operatorname{LVEDD}(\mathrm{cm})$ & $4.71 \pm 0.46$ & $4.61 \pm 0.31$ & 0.442 \\
\hline LVESD (cm) & $3.00 \pm 0.70$ & $2.75 \pm 0.40$ & 0.057 \\
\hline EF. \% & $51.77 \pm 12.25$ & $62.95 \pm 5.75$ & $<0.001$ \\
\hline LA (cm) & $3.72 \pm 0.45$ & $3.64 \pm 0.54$ & 0.170 \\
\hline
\end{tabular}

CK-MB: Creatin kinase myocardial band, COPDB: Chronic obstructive pulmonary disease, DM: diabetes mellitus, EF: Ejection fraction, HDL: High-density lipoprotein, HT: Hypertension, LDL: Low-density lipoprotein, LA: Left atrium, LVEDD: Left ventricle end-diastolic diameter, LVESD: Left ventricle end-systolic diameter, MPV: Mean platelet volume, WBC: White blood cell, WMR: White blood cell count to mean platelet volume ratio.

lipoprotein level was significantly lower in patient group $(41.10 \pm 14.67 \mathrm{mg} / \mathrm{dL}$ vs. $45.53 \pm 13.09 \mathrm{mg} / \mathrm{dL}$, $\mathrm{p}=0.001)$. WBC and neutrophil counts were higher in the patients group compared to the control group $\left(9.14 \pm 3.54 \times 10^{3} / \mathrm{uL}\right.$ vs. $8.03 \pm 2.14 \times 10^{3} / \mathrm{uL}, \mathrm{p}=0.002$ and $6.05 \pm 2.86$ vs. $4.74 \pm 1.69, \mathrm{p}<0,001$; respectively). Lymphocyte and platelet counts were significantly lower in patient group $\left(2.23 \pm 1.24 \times 10^{3} / \mathrm{uL}\right.$ vs. $2.50 \pm 0.69 \times 10^{3} / \mathrm{uL}, \mathrm{p}<0.001$ and $220.22 \pm 63.35 \times 10^{3} /$ uL vs. $266.87 \pm 62.72 \times 10^{3} / u L, p<0.001$; respectively), while creatinine and blood glucose levels were significantly lower in control group $(0.81 \pm 0.83 \mathrm{mg} /$ $\mathrm{dL}$ vs. $1.07 \pm 0.77 \mathrm{mg} / \mathrm{dL}, \mathrm{p}<0.001$ and $104.37 \pm 56.51$ $\mathrm{mg} / \mathrm{dL} \quad$ vs. $155.28 \pm 78.26 \mathrm{mg} / \mathrm{dL}, \quad \mathrm{p}<0.001$; respectively). MPV was lower in patient group compared to the control group $(9.68 \pm 1.34 \mathrm{fL}$ and $10.71 \pm 0.94 \mathrm{fL}$, respectively; $\mathrm{p}<0.001)$. In addition, WMR was found to be significantly greater in the patient group compared to the control group $(960 \pm 37$ and $760 \pm 21$, respectively; $p<0.001)$. As for the echocardiographic parameters, they were similar between two groups except left ventricular ejection fraction which was significantly lower in the patient group compared to the control group $(51.77 \pm 12.25 \%$ and $62.95 \pm 5.75 \%$, respectively; $\mathrm{p}<0.001)$. Median SYNTAX score of the patient group was 11.79 (0-38.5). Moreover, the patient group was further subdivided into 3 tertiles according to the SYNTAX scores as follows: low SYNTAX score tertile (score $\leq 22,141$ patients); 
Table-II: ANOVA analysis of WMR parameter in SYNTAX score tertiles.

\begin{tabular}{ccccc}
\hline Variable & $\begin{array}{c}\text { SYNTAX } \leq 22 \\
\text { (141 patients) }\end{array}$ & $\begin{array}{c}\text { SYNTAX 23-32 } \\
\text { (20 patients) }\end{array}$ & $\begin{array}{c}\text { SYNTAX } \geq 33 \\
\text { (14 patients) }\end{array}$ & P-value \\
\hline WMR & $890 \pm 26$ & $1090 \pm 042$ & $1500 \pm 65$ & $<0.001$ \\
\hline
\end{tabular}

intermediate SYNTAX score tertile (score between 23 and 32, 20 patients); and, high SYNTAX score tertile (score $\geq 33,14$ patients) (Table-II).WMR among low, intermediate and high score tertiles were calculated to be $890 \pm 26,1090 \pm 042$ and $1500 \pm 65$, respectively $(\mathrm{p}<0.001)$. As can be seen from the Table-II, the majority of the patient group had fitted into the low SYNTAX score tertile.

According to ROC curve analysis, a WMR $>960$ showed a sensitivity of $80.6 \%$ and a specificity of $67.6 \%$ in predicting a SYNTAX score $\geq 23$ (AUC: 0.756 ; 95\% CI: 0.685 - 0.818; p<0.0001) (Fig.1). Furthermore, a WMR > 1360 predicted a SYNTAX score $\geq 33$ with a sensitivity of $71.4 \%$ and a specificity of $93 \%$ (AUC: 0.840 ; 95\% CI: 0.777 0.892; $\mathrm{p}<0.0001$ ) (Fig.2).

\section{DISCUSSION}

This study is perhaps the first to show elevated WMR in NSTEMI patients compared with age and comorbidity-matched control subjects. Moreover, our study also demonstrated that baseline WMR increased significantly as the SYNTAX score

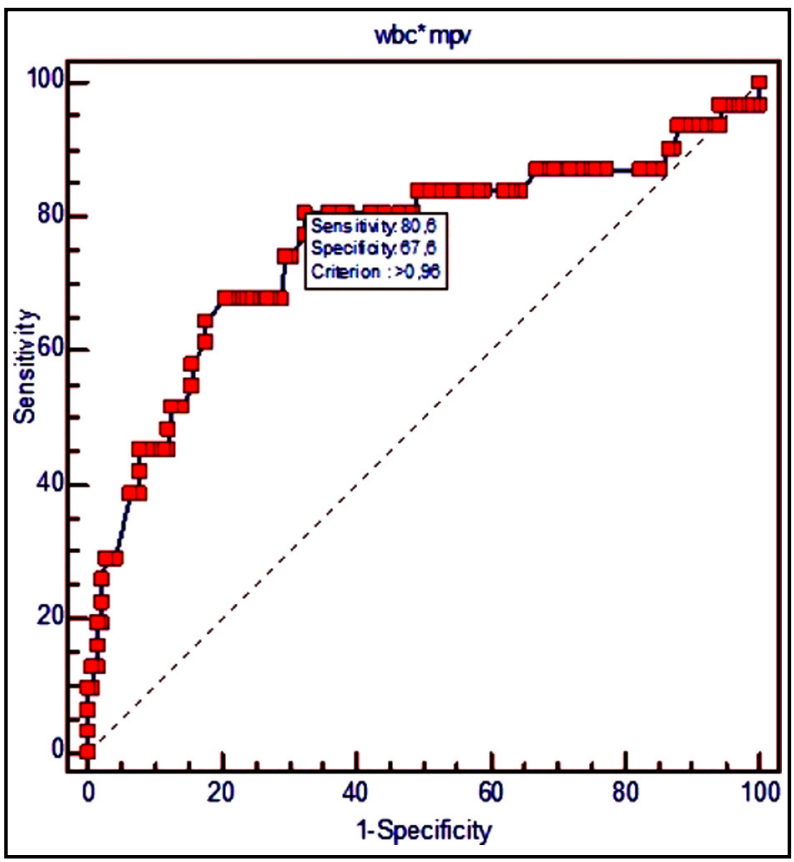

Fig.1: Sensitivity and specificity of WMR variable for predicting SYNTAX score $\geq 23$. increased in patients with NSTEMI, yielding a WMR cut-off value of 960 to predict SYNTAX score $\geq 23$ and another cut-off value of 1360 to predict SYNTAX score $\geq 33$.

Inflammation has long been known to contribute intricately to development, progression and destabilization of atherosclerotic plaques. Platelets, leukocytes and vascular endothelial cells interact with each other through a constellation of mediators or inflammation markers operating concurrently, thereby resulting in atherosclerotic plaque rupture in the setting of ACS..$^{11,12}$ In addition, WBC count and some other hematological indices such as neutrophil count, lymphocyte count, NLR, MPV, RDW and MPV to lymphocyte ratio have previously been reported to have predictive and prognostic value in the setting of ACS. ${ }^{13-19}$

MPV is among the parameters pertaining to platelet activation. Larger platelets are more active and thrombogenic. Although there are studies reporting increase in MPV in ACS patients or patients possessing cardiovascular risk factors, some others yielded conflicting results. ${ }^{13,17,18,20-24}$

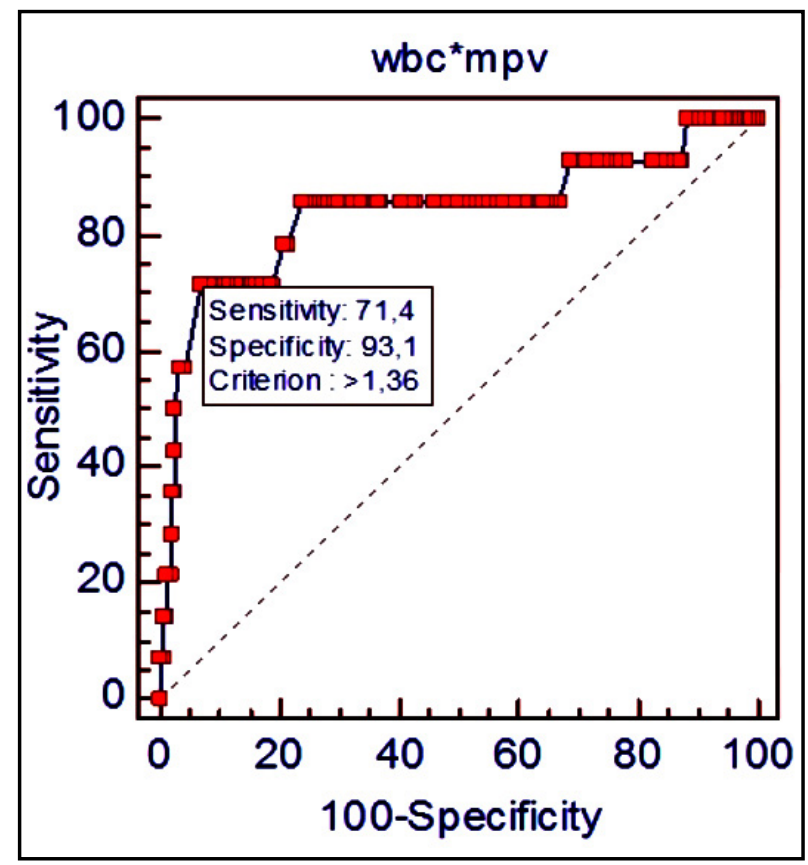

Fig.2: Sensitivity and specificity of WMR variable for predicting SYNTAX score $\geq 33$. 
On the other hand, MPV and platelet count were demonstrated in another study to decrease initially 3 hours after the hospital admission, followed by increase on the $3^{\text {rd }}$ and $7^{\text {th }}$ days in patients with STEMI and NSTE-ACS. ${ }^{25}$ The fact that platelet count and MPV were significantly lower in patient group than in control group may in part be explained consumption and sequestration of platelets, especially those with later volume, during the acute phase of ACS. ${ }^{25}$

Likewise, WMR has emerged as a novel inflammatory marker with documented efficacy in the prediction of prognosis in ACS. Dehghani MR et al. ${ }^{13}$ reported that WMR was stronger in predicting long-term adverse outcomes than other complete blood cell indices in patients with NSTEMI. Similarly, Cicek G et al. ${ }^{19}$ documented higher admission WMR to be better predicted long-term mortality compared to such complete blood count indices as MPV, RDW, PLR and NLR in patients with STEMI. In a recent study by Adam AM et al. ${ }^{18}$, WMR on admission was more significant positive correlation with increased short-term mortality compared to other complete blood cell indices. Additionally, their study also reported that ACS patients with WMR>1000 on admission were associated with higher rates of multi-vessel disease, higher incidence of mortality and greater Thrombolysis in Myocardial Infarction (TIMI) Score, compared to those with admission WMR $<1000$. Accordingly, cut-off values of 960 and 1360 to predict SYNTAX scores $\geq 23$ and $\geq 33$, respectively, seem quite similar to that study. SYNTAX score has been a widely accepted scoring system which is utilized to assess the disease complexity of entire coronary arterial system and helps clinicians stratify the potential patients most likely to benefit either from PCI or CABG surgery. ${ }^{10,26}$ Moreover, the higher the SYNTAX score, the worse the adverse cardiovascular outcomes and the more complicated the CAD in a particular case. ${ }^{26}$ Considering our study findings in this regard, it is prudent to anticipate increase in WMR values with increasing SYNTAX score and hence short and long term mortality.

Limitations of the study: First, our study was a single center study with relatively small number of recruitment. We did not interrogate any probable relationship between other complete blood count parameters and SYNTAX scores of the patient group. We also did not compare the groups and SYNTAX score tertiles on the gender basis.

\section{CONCLUSION}

WMR value was significantly elevated in NSTEMI patients, compared to the age and comorbiditymatched controls. Moreover, higher WMR was positively correlated with greater SYNTAX score in the setting of NSTEMI. WMR is likely to be utilized in predicting the severity of the CAD and to implement risk stratification in patients with NSTEMI. However, further studies are needed to validate our study findings.

\section{Grant Support \& Financial Disclosures: None.}

\section{REFERENCES}

1. Libby P. Mechanisms of acute coronary syndromes and their implications for therapy. N Engl J Med. 2013;368:20042013. doi: 10.1056/NEJMra1216063.

2. Sanchis-Gomar F, Perez-Quilis C, Leischik R, Lucia A. Epidemiology of coronary heart disease and acute coronary syndrome. Ann Transl Med. 2016;4(13):1-12. doi: 10.21037/ atm.2016.06.33.

3. Barron HV, Cannon CP, Murphy SA, Braunwald E, Gibson $\mathrm{CM}$. Association between white blood cell count, epicardial blood flow, myocardial perfusion, and clinical outcomes in the setting of acute myocardial infarction: A thrombolysis in myocardial infarction 10 substudy. Circulation. 2000;102:2329-2334.

4. Chung S, Song YB, Hahn JY, Chang SA, Lee SC, Choe $\mathrm{YH}$, et al. Impact of white blood cell count on myocardial salvage, infarct size, and clinical outcomes in patients undergoing primary percutaneous coronary intervention for ST-segment elevation myocardial infarction: A magnetic resonance imaging study. Int $\mathrm{J}$ Cardiovasc Imag. 2014;30:129-136. doi: 10.1007/s10554-013-0303-x.

5. Corash L, Tan H, Gralnick HR. Heterogeneity of human whole blood platelet subpopulations. I. Relationship between buoyant density, cell volume, and ultrastructure. Blood. 1977;49:71-87.

6. Karpatkin S. Heterogeneity of human platelets. I. Metabolic and kinetic evidence suggestive of young and old platelets. J Clin Invest. 1969;48:1073-1082.

7. Huckzek Z, Kochman J, Filipiak KJ, Horszczaruk GJ, Grabowski M, Piatkowski R, et al. Mean platelet volume on admission predicts impaired reperfusion and longterm mortality in acute myocardial infarction treated with primary percutaneous coronary intervention. J Am Coll Cardiol. 2005;46(2): 284-290.

8. Maden O, Kacmaz F, Selcuk H, Selcuk MT, Aksu T, Tufekcioglu O, et al. Relationship of admission hematological indexes with myocardial reperfusion abnormalities in acute ST segment elevation myocardial infarction patients treated with primary percutaneouscoronary interventions. Can J Cardiol. 2009;25(6):e164-168.

9. Roffi M, Patrono C, Collet JP, Mueller C, Valgimigli M, Andreotti F, et al. ESC guidelines for the management of acute coronary syndromes in patients presenting without persistent ST-segment elevation: task force for the management of acute coronary syndromes in patients presenting without persistent ST-segment elevation of the European Society of Cardiology (ESC). Euro Heart J. 2015;37(3):267-315. doi: 10.1093/ eurheartj/ehv320. 
10. Sianos G, Morel MA, Kappetein AP, Morice MC, Colombo A, Dawkins K, et al. The SYNTAX score: an angiographic tool grading the complexity of coronary artery disease. Euro Intervention. 2005;1(2):219-227.

11. Davi G, Patrono C. Platelet activation and atherothrombosis. N Engl J Med. 2007;357:2482-2494.

12. Botto N, Sbrana S, Trianni G, Andreassi MG, Ravani M, Rizza A, et al. An increased platelet-leukocytes interaction at the culprit site of coronary artery occlusion in acute myocardial infarction: A pathogenic role for no-reflow phenomenon? Int J Cardiol. 2007;117(1):123-130.

13. Dehghani MR, Rezaei Y, Taghipour-Sani L. White blood cell count to mean platelet volume ratio as a novel noninvasive marker predicting long-term outcomes in patients with non-ST elevation acute coronary syndrome. Cardiol J. 2015;22:437-445. doi: 10.5603/CJ.a2015.0015.

14. Yayla C, Akboga MK, Canpolat U, Akyel A, Yayla KG, Doğan $\mathrm{M}$, et al. Platelet to lymphocyte ratio can be a predictor of infarct-related artery patency in patients with ST-segment elevation myocardial infarction. Angiology. 2015;66:831-836. doi: 10.1177/0003319715573658.

15. Sahin DY, Elbasan Z, Gur M, Yildiz A, Akpinar O, Icen YK, et al. Neutrophil to lymphocyte ratio is associated with the severity of coronary artery disease in patients with ST-segment elevation myocardial infarction. Angiology. 2013;64:423-429. doi: 10.1177/0003319712453305.

16. Uyarel H, Ergelen M, Cicek G, Kaya MG, Ayhan E, Turkkan $\mathrm{C}$, et al. Red cell distribution width as a novel prognostic marker in patients undergoing primary angioplasty for acute myocardial infarction. Coron Artery Dis. 2011;22:138144. doi: 10.1097/MCA.0b013e328342c77b.

17. Elbasan Z, Gur M, Sahin DY, Kuloglu O, Icen YK, Turkoglu $\mathrm{C}$, et al. Association of mean platelet volume and preand post interventional flow with infarct-related artery in ST-segment elevation myocardial infarction. Angiology. 2013;64:440-446. doi: 10.1177/0003319712455685.

18. Adam AM, Rizvi AH, Haq A, Naseem R, Rehan A, Shaikh AT, et al Prognostic value of blood count parameters in patients with acute coronary syndrome. Indian Heart J. 2018;70(2):233-240. doi: 10.1016/j.ihj.2017.06.017.

19. Çiçek G, Açikgöz SK, Yayla Ç, Kundi H, İleri M. White blood cell count to mean platelet volume ratio: a novel and promising prognostic marker for ST-segment elevation myocardial infarction. Cardiol J. 2016;23(3):225-235. doi 10.5603/CJ.a2016.0001.
20. Leader A, Pereg D, Lishner M. Are platelet volume indices of clinical use? A multidisciplinary review. Ann Med. 2012;44(8):805-816. doi: 10.3109/07853890.2011.653391.

21. Martin JF, Bath PM, Burr ML. Influence of platelet size on outcome after myocardial infarction. Lancet. 1991;338(8780):1409-1411.

22. López-Cuenca AA, Tello-Montoliu A, Roldán V, PérezBerbel P, Valdés M, Marín F. Prognostic Value of Mean Platelet Volume in Patients With Non-ST-Elevation Acute Coronary Syndrome. Angiology. 2012;63(4):241-244. doi: 10.1177/0003319711413892.

23. Endler G, Klimesch A, Sunder-Plassmann H, Schillinger $M$, Exner M, Mannhalter C, et al. Mean platelet volume is an independent risk factor for myocardial infarction but not for coronary artery disease. Br J Haematol. 2002;117:399-404.

24. Estévez-Loureiro R, Salgado-Fernández J, Marzoa-Rivas R, Barge-Caballero E, Pérez-Pérez A, Noriega-Concepción $\mathrm{V}$, et al. Mean platelet volume predicts patency of the infarct-related artery before mechanical reperfusion and short-term mortality in patients with ST-segment elevation myocardial infarction undergoing primary percutaneous coronary intervention. Thromb Res. 2009;124(5):536-540. doi: 10.1016/j.thromres.2009.03.012

25. Sušilović Grabovac Z, Baković D, Lozo M, Pintarić I, Dujić Ž. Early Changes in Platelet Size and Number in Patients with Acute Coronary Syndrome. Int J Angiol. 2017;26(4):249-252. doi: 10.1055/s-0037-1607048.

26. Bundhun PK, Sookharee $Y$, Bholee A, Huang F. Application of the SYNTAX score in interventional cardiology: A systematic review and meta-analysis. Medicine (Baltimore). 2017;96(28):e7410. doi: 10.1097/MD.0000000000007410.

\section{Author`s Contribution:}

SS conceived and designed.

SS and ES did statistical analysis \& editing of manuscript.

MC, SCO and AY did data collection and manuscript writing.

YB did review and final approval of manuscript.
Authors:

1. Dr. Serkan Sivri,

2. Dr. Erdogan Sokmen,

3. Dr. Mustafa Celik,

4. Dr. Sinan Cemgil Ozbek,

5. Dr. Alp Yildirim,

6. Dr. Yalcin Boduroglu,

1-6: Department of Medicine, Ahi Evran University Training and Research Hospital, Kirsehir, Turkey. 